\title{
(2) OPEN ACCESS \\ Olfactory groove meningioma with a 10-year history of smell loss and olfactory recovery after surgery
}

\author{
Andreas Steenholt Niklassen (D) 1,2 Rasmus Langelund Jørgensen, ${ }^{3}$ \\ Alexander Wieck Fjaeldstad (D) 1,2
}

FFlavour Institute, Department of Clinical Medicine, Aarhus Universitet, Aarhus C, Denmark ${ }^{2}$ Department of Ear, nose and throat, Regional Hospital West, Holstebro, Denmark

${ }^{3}$ Department of Neurosurgery, Aarhus University Hospital, Aarhus N, Denmark

Correspondence to Dr Andreas Steenholt Niklassen; an@clin.au.dk

Accepted 8 August 2021
Check for updates

(c) BMJ Publishing Group Limited 2021. Re-use permitted under CC BY-NC. No commercial re-use. See rights and permissions. Published by BMJ.

To cite: Niklassen AS, Jørgensen RL, Fiaeldstad AW. BMJ Case Rep 2021;14:e244145. doi:10.1136/bcr-2021244145

\section{SUMMARY}

A rare cause of olfactory impairment is olfactory groove meningiomas with insidious onset of nonspecific symptoms like headache, olfactory dysfunction, psychiatric symptoms such as depression, personality changes, declining cognitive function, visual disturbances or seizures. A common complication of surgery is loss of olfactory function. Still, the preservation of olfactory function should be attempted as olfactory loss often has a severe negative impact on quality of life. This report describes a woman with an olfactory groove meningioma and a 10-year history of olfactory impairment. It includes preoperatively and postoperatively extended olfactory testing, a neurosurgical approach to preserve the olfactory function and postoperative olfactory rehabilitation. After rehabilitation, the patient regained a normal olfactory function, even though the right-sided olfactory nerve could not be preserved during surgery. The case demonstrates the importance of performing neuroimaging in selected patients with olfactory loss and a method for preserving and potentially improving postoperative olfactory function.

\section{BACKGROUND}

Clinical knowledge of how and when to refer patients with olfactory impairment to further investigations is paramount. A rare cause of olfactory impairment is olfactory groove meningiomas (OGM)-representing 5\%-18\% of intracranial meningiomas. ${ }^{1}$ The prevalence of pathologically confirmed meningiomas in the USA is $97.5 / 100$ 000 , with an incidence rate of 8.36 for females and 3.61 for males out of 100000 person-years. $^{2}$ OGMs are benign, slow-growing tumours with usually insidious onset of non-specific symptoms like headache, olfactory dysfunction, psychiatric symptoms such as depression, personality changes, declining cognitive function, visual disturbances or seizures. ${ }^{134}$

A common complication of surgery for OGMs is loss of residual or severely impaired olfactory function. However, the preservation of olfactory function should be attempted ${ }^{5}$ as olfactory loss has a severe negative impact on quality of life. ${ }^{6}$

This report describes the management of a woman with an OGM and a 10-year history of olfactory impairment. The report includes preoperatively and postoperatively extended olfactory testing with evaluation in a specialised smell and taste clinic, a neurosurgical approach to preserve the olfactory function and postoperative olfactory rehabilitation.
Furthermore, the case demonstrates the importance of performing neuroimaging in selected patients with olfactory loss and a method for preserving and potentially improving postoperative olfactory function in OGM induced olfactory loss.

\section{CASE PRESENTATION}

The case presents a fit-and-well 56-year-old woman with a 10-year history of gradually decreasing olfactory function. The patient had 1.5 years previously been diagnosed with stress, and as a result, reduced her work capacity from full time to part time. This stress particularly influenced the patient's ability for complex processing of tasks at hand, and the patient had to take one subtask at a time. During the previous 6 months, the patient had suffered from intermittent headaches but no history of nausea or vomiting. Our case begins as the patient was admitted to the emergency department with a first-time generalised seizure. Objective examination, including neurological examination, was normal, except for slight suspicion of dysarthria, which resolved.

\section{INVESTIGATIONS}

On admission to the emergency department, an acute CT scan followed by a gadolinium-enhanced cerebral MRI was performed. These scans revealed an extra-axial mass on the anterior skull base with extension to the right frontal lobe, with homogeneous contrast uptake and significant perilesional oedema (see figure 1). The largest diameter of the mass was $30 \mathrm{~mm}$ (see figure 2). A multidisciplinary team conference was conducted with attendings from the neurosurgical, oncological, neurological and neuroradiological departments. Radiologically, the most likely diagnosis was an OGM, and the patient was referred to the neurosurgical department for assessment and treatment. As the tumour was symptomatic with perilesional oedema, informed consent for surgery was obtained. Before the scheduled surgery, the patient was referred to the Flavour smell and taste clinic for preoperative and postoperative examination of the olfactory function. The olfactory function was preoperatively tested with the extended version of the Sniffin' Sticks ${ }^{7}$ (Burghart Messtechnik, Wedel, Germany) with a threshold score (T) of 2, discrimination score (D) of 7 and identification score (I) of 11. A total TDI score of 20-indicating severe hyposmia. No other causes of olfactory dysfunction were found. 


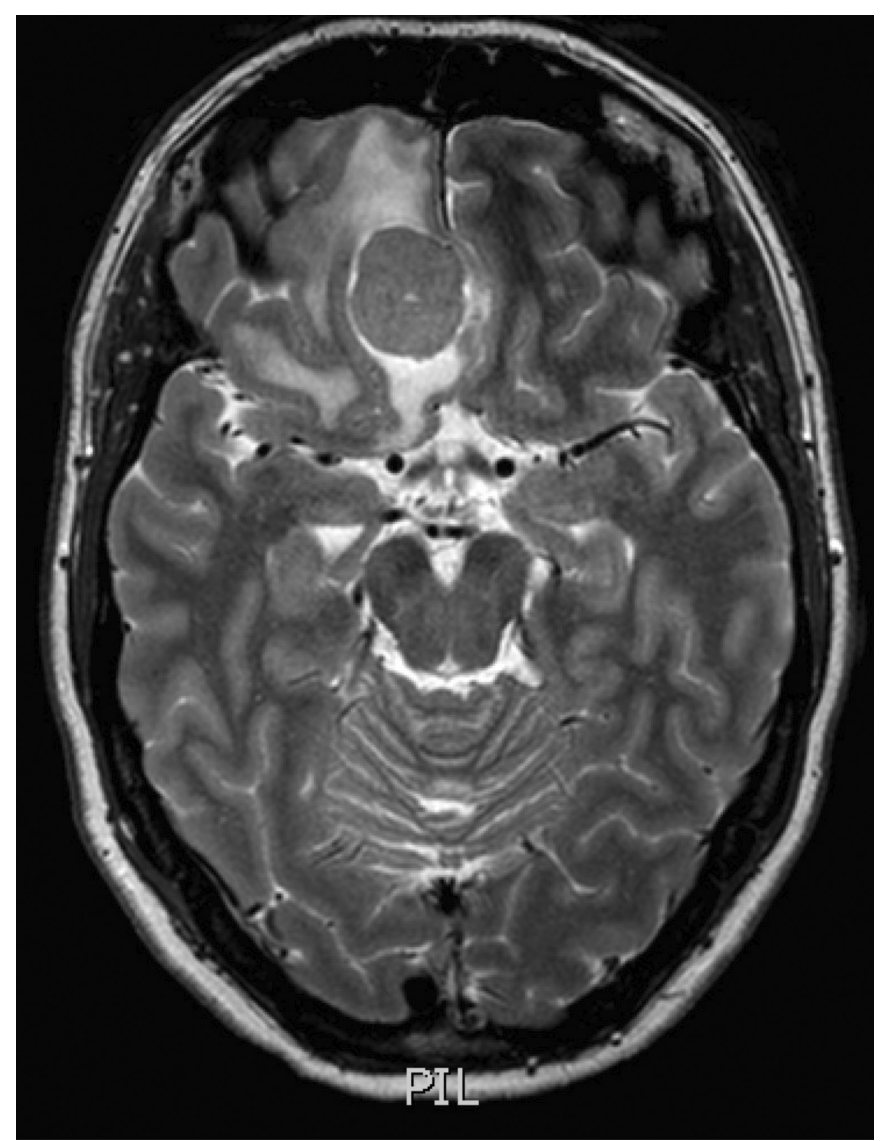

Figure 1 Axial T2-weighted MRI showing the tumour and peritumoural oedema.

\section{TREATMENT}

\section{Pharmacological}

The patient presented with generalised seizures, and antiepileptic medication with lamotrigine was prescribed. Due to increasing headaches and radiologically confirmed substantial white matter changes suggesting oedema, she was supplemented with oral steroids before surgery.

\section{Surgical}

Based on the primarily right-sided basofrontal location, the absence of paranasal sinus infiltration and that the patient had intact but diminished olfactory function, a right-sided pterional craniotomy was performed to salvage the olfactory apparatus. Perioperatively, the right olfactory tract was found stretched around the basolateral side of the tumour and could not be preserved. The left olfactory tract was left intact. The tumour was completely resected, and the dural attachment coagulated, corresponding to a Simpson grade II resection.

\section{OUTCOME AND FOLLOW-UP}

The immediate postoperative course was uneventful. However, on postoperative day 2, the patient had a generalised tonicclonic seizure. The postoperative generalised seizure was abolished with intravenous diazepam and an increased dose of prophylactic lamotrigine with no further seizures. An acute CT scan showed expected postoperative changes with minimal blood in the tumour bed. The patient was discharged from the hospital on day three. Histological examination confirmed a benign meningioma. Follow-up contrast MRIs 3 and 12 months

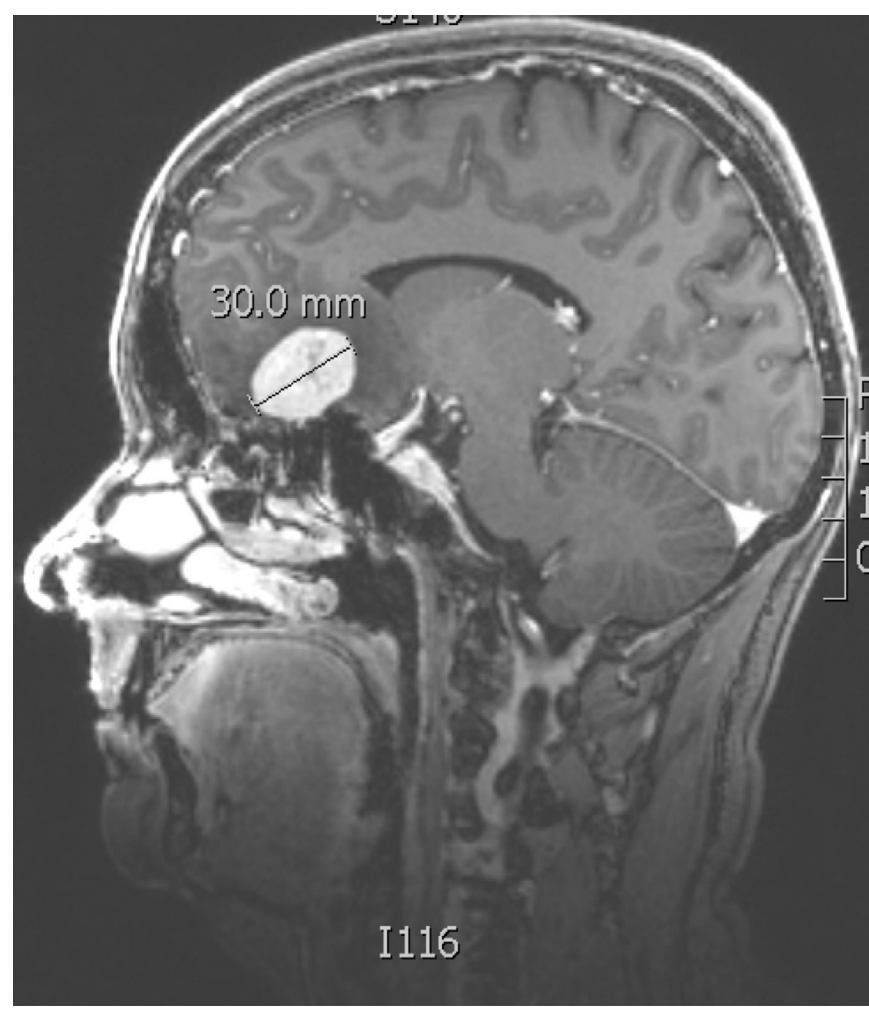

Figure 2 Sagittal gadolinium-enhanced T1-weighted MRI showing the size and classic location of OGM. OGM, olfactory groove meningioma.

postoperatively were without evidence of recurrence, and the oedema had subsided.

Due to complaints of reduced short-term memory and concentration difficulties, the patient was referred for neuropsychological testing and referred to further neurocognitive rehabilitation. Despite rehabilitation, the patient still suffered from reduced working memory and problems handling more complex tasks one year after surgery. Consequently, the patient was not yet able to return to her part-time job.

At the flavour clinic, follow-up was performed 12 months after surgery, where the olfactory function was retested with the extended Sniffin' Sticks test. ${ }^{7}$ The TDI score had improved to 33 (an improvement from 20), with a threshold score of 4, a discrimination score of 14 and an identification score of 15 . This reflects a normal olfactory function-a significant improvement from the presurgical olfactory function.

\section{DISCUSSION}

Olfactory impairment is prevalent in $15 \%$ of the general population. ${ }^{8}$ Most patients are diagnosed with an underlying aetiology, but up to $23 \%$ remain with no apparent cause and are subsequently classified as idiopathic. ${ }^{9}$ Typically, these patients are referred for further investigations with MRI to rule out potentially treatable intracranial disease. However, the hit rate of MRI revealing an underlying treatable central cause of olfactory dysfunction in idiopathic anosmics/hyposmics is as low as $0.08 \%$, according to Rudmik et al. ${ }^{10}$ Hoekman et al investigated 130 cases of idiopathic olfactory loss, and only one finding of multiple sclerosis $(0.8 \%)$ was potentially the cause of olfactory dysfunction. ${ }^{11}$ Decker et al investigated 122 cases of idiopathic smell loss and found 31 cases of causal findings for dysosmia. Most of these were due to sinusitis, but two cases of olfactory meningioma were found $(1.6 \%) .^{12}$ 
This calls for debate whether MRI should be standard practice in idiopathic olfactory loss or be reserved for cases with a higher clinical risk of intracranial disease. A recent study examined a modelling-based economic evaluation of routine MRI for idiopathic olfactory loss. It found that while MRI (US\$2400) had a $100 \%$ sensitivity in diagnosing intracranial tumours, the no-imaging strategy (US\$86) had a $98 \%$ sensitivity. ${ }^{10}$ The incremental cost per diagnosis for the MRI strategy compared with the no-imaging strategy was US\$115 669.50. They conclude the most cost-effective strategy is not to perform routine MRI in these patients and that it could be cost-effective in cases when the a priori clinical probability of treatable intracranial disease reaching $7.9 \% .^{10}$

Our case describes the importance of correct diagnostics and treatment for olfactory meningioma and potential good outcome with preservation-and even improvement-of the olfactory function. In the present case, the improvement in olfactory function can most likely be prescribed to reduced oedema on the left side following resection of the right-sided tumour. Preoperatively, the right-sided olfactory function was impaired by the tumour and the left-sided olfactory function by significant oedema. During surgery, the right-sided nerve was not preserved due to tumour growth and had to be removed. This completely removed the right-side olfactory function postoperatively. After surgery, the oedema diminished, and the leftsided nerve regained normal function. To find the needle in the haystack, it is paramount to identify which symptoms warrant an MRI scan. The most frequent presenting symptoms include mono-symptomatic headache, personality changes, olfactory dysfunction or visual impairment. ${ }^{13}$

In the current case, olfactory dysfunction was present for 10 years, headaches for 6 months and disabling psychiatric stressrelated symptoms for 18 months before diagnosis. Using the suggested MRI strategy, the patient should have been correctly diagnosed sooner, which may have reduced the load of cognitive difficulties after surgery. However, further studies are needed to investigate this diagnostic pipeline.

Olfactory dysfunction ranging from hyposmia to complete anosmia is an early symptom of OGMs and found in 58.5\%$71.7 \%$ of patients with OGMs., ${ }^{4} 14$ but only $6.4 \%-15 \%$ of patients have olfactory dysfunction as their presenting symptom. ${ }^{145}$ Extended olfactory testing is not routinely performed in patients with OGMs, and olfactory outcomes following surgery are variably tested and reported. ${ }^{15}{ }^{15-17}$ The surgical treatment carries a high risk, up to $89.7 \%$, of decreased or complete loss of olfactory. ${ }^{1}$ However, as the olfactory function is only rarely tested preoperatively and postoperatively, the true incidence of preoperative dysfunction is unknown, and the complication rate of deteriorating olfactory function likely under-reported.

Numerous reports suggest that the risk depends on the surgical approach, with unilateral approaches are more likely to preserve preoperative olfactory function. ${ }^{518}$ Besides a higher risk of postoperative anosmia, the classic bilateral subfrontal approach has higher morbidity and mortality than unilateral approaches. ${ }^{4} 1416$ Besides the classic transcranial approaches within the last decade, endoscopic endonasal resection of OGM's through the cribriform plate has been explored as a minimally invasive procedure to reduce surgical morbidity. Even though this technique seems to be advantageous with regards to visual outcome when it comes to olfactory function, this technique carries a higher risk of anosmia as well as postoperative cerebrospinal fluid leak increasing the risk of postoperative meningitis and the need for reoperation. $^{19} 20$
Gerber et al report on a patient with a large OGM with preoperative anosmia treated with a bifrontal craniotomy and careful dissection of the olfactory tracts. At follow-up, after 15 months,

\section{Patient's perspective}

About 10 years ago, I started noticing my sense of smell was deteriorating gradually, but, at the moment, I thought it was just an average age decline. About 1.5 years before discovering the meningioma, I was diagnosed with stress, which happened after an episode where I couldn't even find my own home, and someone else had to walk me home. I was on sick leave for 6 months and was in a terrible condition during that time. I started working again but couldn't handle my job full time, so I worked part-time after that. From the stress diagnosis and until discovering the meningioma, I still had ups and downs. I remember many headaches and had to stay in bed for several days at different times during that period. One night, I went into generalised seizures, where my husband found me, and I was brought into the emergency department at the hospital, where I had a scan that discovered the meningioma. Two months went by before I was scheduled for surgery. Before surgery, I had a preoperative status of the function of my smell, which accounted to severely reduced sense of smell.

I had the surgery done in December 2019, and I was really in a terrible condition the following month; and I think If I had been 20 years older, I wouldn't have made it. At least not mentally — maybe physically. I tried getting back to work, which had been my plan, and I started part-time with 4-6hours a week gradually increasing, but I just couldn't handle it anymore. Primarily because of the fatigue, but maybe also my lack of ability to have an overview of things. Secondarily, I had memory issues, concentration issues, and difficulties speaking and understanding spoken words when I was tired or fatigued. Furthermore, I was often confused and dizzy. I was used to having lots of things going on simultaneously, working as a department manager, but I just couldn't anymore. Nothing worked; I couldn't read —it just didn't stay with me. And I was tired all the time. My concentration and memory were terrible. It still is. I was referred to neurorehabilitation at a centre, where I stayed for 3 months, which was terrific, and I learnt many strategies to cope. I feel much better now, even though I had to go on early retirement and stopped working. I still have to sleep during the day to make it through the day. Focusing on my sense of smell, it has definitely improved after the surgery, as it was almost completely gone presurgery. I think the smell training helped me improve, but I stopped doing it eventually. Everyone in the healthcare system helped me, and I am so grateful for the people who cared for me during the most challenging period of my life.

\section{Learning points}

- In patients with olfactory loss and concomitant headache, personality change or visual impairment, MRI should always be performed.

- When choosing the correct surgical strategy, olfactory function can be preserved - and potentially improvedfollowing surgery in olfactory groove meningioma (OGM) patients.

- A multidisciplinary approach for presurgical and postsurgical treatment of OGM is recommended to improve overall outcome and quality of life. 
the patient had regained her sense of smell. ${ }^{21}$ Also, Bassiouni et al report improving olfactory function in two $(4,9 \%)$ patients following surgery. ${ }^{4}$

Our case encourages the use of the pterional approach for OGMs. By preserving the contralateral olfactory tract, preoperative hyposmia can even improve following complete tumour removal. Furthermore, it underlines the need for more studies with thorough preoperative and postoperative olfactory testing to fully uncover the extent of olfactory dysfunction due to OGMs and the potential to improve this overseen neurological deficit by choosing the correct surgical approach. In cases where the laterality of remaining olfactory function is uncertain based on neuroimaging, unilateral olfactory testing on both sides can be advantageous.

Twitter Andreas Steenholt Niklassen @AndreasNiklasse

Contributors ASN, AWF and RLJ were involved in diagnostics and treatment of the patient. ASN wrote the initial draft of the paper. The patient wrote the patients perspective section and read and approved the paper. All authors revised the paper critically. All authors are guarantors of the paper.

Funding The authors have not declared a specific grant for this research from any funding agency in the public, commercial or not-for-profit sectors.

Competing interests None declared.

Patient consent for publication Obtained.

Provenance and peer review Not commissioned; externally peer reviewed.

Open access This is an open access article distributed in accordance with the Creative Commons Attribution Non Commercial (CC BY-NC 4.0) license, which permits others to distribute, remix, adapt, build upon this work non-commercially, and license their derivative works on different terms, provided the original work is properly cited and the use is non-commercial. See: http://creativecommons.org/ licenses/by-nc/4.0/.

\section{ORCID iDs}

Andreas Steenholt Niklassen http://orcid.org/0000-0003-4535-127X

Alexander Wieck Fjaeldstad http://orcid.org/0000-0002-9135-6920

\section{REFERENCES}

1 Fountas KN, Hadjigeorgiou GF, Kapsalaki EZ, et al. Surgical and functional outcome of olfactory groove meningiomas: lessons from the past experience and strategy development. Clin Neurol Neurosurg 2018;171:46-52.
2 Wiemels J, Wrensch M, Claus EB. Epidemiology and etiology of meningioma. J Neurooncol 2010;99:307-14.

3 Bakay L. Olfactory meningiomas. The missed diagnosis. JAMA 1984;251:53-5.

4 Bassiouni H, Asgari S, Stolke D. Olfactory groove meningiomas: functional outcome in a series treated microsurgically. Acta Neurochir 2007;149:109-21; discussion 121.

5 Jang W-Y, Jung S, Jung T-Y, et al. Preservation of olfaction in surgery of olfactory groove meningiomas. Clin Neurol Neurosurg 2013;115:1288-92.

6 Croy I, Nordin S, Hummel T. Olfactory disorders and quality of life--an updated review. Chem Senses 2014;39:185-94.

7 Niklassen AS, Ovesen T, Fernandes H, et al. Danish validation of Sniffin' sticks olfactory test for threshold, discrimination, and identification. Laryngoscope 2018:128:1759-66.

8 Landis BN, Konnerth CG, Hummel T. A study on the frequency of olfactory dysfunction. Laryngoscope 2004;114:1764-9.

9 Fjaeldstad A, Stankovic J, Onat M, et al. Patients and experiences from the first Danish flavour clinic. Dan Med J 2020;67:5.

10 Rudmik L, Smith KA, Soler ZM, et al. Routine magnetic resonance imaging for idiopathic olfactory loss: a modeling-based economic evaluation. JAMA Otolaryngol Head Neck Surg 2014;140:911-7.

11 Hoekman PK, Houlton JJ, Seiden AM. The utility of magnetic resonance imaging in the diagnostic evaluation of idiopathic olfactory loss. Laryngoscope 2014;124:365-8.

12 Decker JR, Meen EK, Kern RC, et al. Cost effectiveness of magnetic resonance imaging in the workup of the dysosmia patient. Int Forum Allergy Rhinol 2013;3:56-61.

13 Mukherjee S, Thakur B, Corns R, et al. Resection of olfactory groove meningioma - a review of complications and prognostic factors. Br J Neurosurg 2015;29:685-92.

14 Nakamura M, Struck M, Roser F, et al. Olfactory groove meningiomas: clinical outcome and recurrence rates after tumor removal through the frontolateral and bifrontal approach. Neurosurgery 2007;60:844-52; discussion 844-52.

15 Ung TH, Yang A, Aref $\mathrm{M}$, et al. Preservation of olfaction in anterior midline skull base meningiomas: a comprehensive approach. Acta Neurochir 2019;161:729-35.

16 Bitter AD, Stavrinou LC, Ntoulias G, et al. The role of the Pterional approach in the surgical treatment of olfactory groove meningiomas: a 20-year experience. J Neurol Surg B Skull Base 2013;74:97-102.

17 Welge-Luessen A, Temmel A, Quint C, et al. Olfactory function in patients with olfactory groove meningioma. J Neurol Neurosurg Psychiatry 2001;70:218.

18 Nanda A, Maiti TK, Bir SC, et al. Olfactory groove meningiomas: comparison of extent of frontal lobe changes after lateral and Bifrontal approaches. World Neurosurg 2016:94:211-21.

19 Shetty SR, Ruiz-Treviño AS, Omay SB, et al. Limitations of the endonasal endoscopic approach in treating olfactory groove meningiomas. A systematic review. Acta Neurochir 2017;159:1875-85.

20 Purohit A, Jha R, Khalafallah AM, et al. Endoscopic endonasal versus transcranial approach to resection of olfactory groove meningiomas: a systematic review. Neurosurg Rev 2020;43:1465-71.

21 Gerber M, Vishteh AG, Spetzler RF. Return of olfaction after gross total resection of an olfactory groove meningioma: case report. Skull Base Surg 1998:8:229-31.

Copyright 2021 BMJ Publishing Group. All rights reserved. For permission to reuse any of this content visit

https://www.bmj.com/company/products-services/rights-and-licensing/permissions/

BMJ Case Report Fellows may re-use this article for personal use and teaching without any further permission.

Become a Fellow of BMJ Case Reports today and you can:

- Submit as many cases as you like

- Enjoy fast sympathetic peer review and rapid publication of accepted articles

Access all the published articles

Re-use any of the published material for personal use and teaching without further permission

Customer Service

If you have any further queries about your subscription, please contact our customer services team on +44 (0) 2071111105 or via email at support@bmj.com.

Visit casereports.bmi.com for more articles like this and to become a Fellow 